\title{
MI NOMBRE ES NADIE Y NADIE ME LLAMAN TODOS... SOBRE LA IDENTIDAD DEL INMIGRANTE
}

\author{
Fedra Cuestas
}

Considerando un paralelismo entre distintos ámbitos del discurso del poder que clasifica a los inmigrantes, se intenta develar la lógica que lo subyace. A continuación de ello, se busca pensar las consecuencias de este discurso, y las problemáticas que produce a quienes son nombrados por él. Este artículo plantea una reflexión concerniente a las secuelas y los riesgos que implica la ausencia de reconocimiento social de la cual son objeto algunas categorías de inmigrantes.

Palabras clave: Inmigrantes; Identidad; Reconocimiento; Deshumanización.

«Qui a volé leur histoire

Qui a vole leur mémoire

Qui a piétiné leur vie

Comme on marche sur un miroir...»**

\section{Introducción}

El psiquiatra Joseba Achotegui ${ }^{1}$ postula la aparición de un cuadro clínico reactivo, que aparece como consecuencia de un proceso migratorio. Según el autor, esta patología, denominada "Síndrome del inmigrante con estrés crónico y múltiple" o "Síndrome de Ulises", respondería a situaciones calificadas como "extremas", y se desarrollaría frente a un "estrés límite".

\footnotetext{
Profesora Universidad Nacional Andrés Bello, Chile. Becaria Conicyt, Candidata a Doctora en Filosofía, Universidad de Paris VIII Vincennes- Saint Denis, Francia. Magíster en Derechos y Necesidades de la Infancia y la Adolescencia, Universidad Autónoma de Madrid, España. D.U. en Antropología y Psicopatología, Universidad de Paris 6, Francia. Psicóloga, Universidad Nacional de Córdoba, Argentina. Correo electrónico: fedracuestas@hotmail.com. Santiago/Chile.

** Extracto tomado de una canción de Michel Berger, denominada « Chanter pour ceux qui sont loin de chez eux ».

${ }^{1}$ ACHOTEGUI, Joseba. Emigrar en situación extrema: el Síndrome del inmigrante con estrés crónico y múltiple (Síndrome de Ulises), p. 39-52.
} 
Este psiquiatra cree que emigrar hoy confronta a niveles de estrés tan intensos que llegan a superar la capacidad de adaptación de los seres humanos. En las descripciones que él realiza menciona que estas situaciones afectarían de manera más específica a los inmigrantes llamados "sin papeles". Indagando en la lógica que subyace a esta última denominación, observamos un paralelismo entre ella y la categoría diagnostica antes asignada a los inmigrantes. Consideramos entonces el "Síndrome de Ulises" como una manifestación más de representaciones sociales vigentes sobre ciertos inmigrantes, intentando dejar a la vista su significación.

Frente al discurso del poder que asignando nombres, habla por y de los inmigrantes, nos preguntamos sobre la verdadera problemática de la cual ellos son objeto. El presente artículo se propone reflexionar sobre los espacios sociales asignados a los inmigrantes cuyos documentos de identidad son desconocidos, desvalorizados, discriminados. Se pretende cuestionar todo discurso del poder que afecte al inmigrante, entendiendo como parte de ello al discurso psiquiátrico patologizante. Examinaremos diversas calificaciones con sentidos semejantes, dadas a estos inmigrantes, buscando mostrar las incidencias que para ellos puede tener un reconocimiento social fallido. Finalmente, recordando la historia reciente y no acabada de las migraciones, se intentará alertar respecto a un pasado siempre cercano y posible de ser repetido.

\section{Calificaciones y descalificaciones}

Toda migración requiere del pasaje por fronteras (entre una zona rural y la ciudad, entre diferentes regiones, entre diferentes Estados, etc.). Los trámites administrativos requeridos para atravesar una frontera producen clasificaciones, calificaciones y descalificaciones. Las clasificaciones de inmigrantes buscan asignar categorías comunes a realidades muy diversas. Se crean subcategorías que implican grados de valorización diferentes de estatutos sociales. El pasaporte registra una distinción que muestra el grado obtenido (turista, estudiante, trabajador, familiar de extranjero, etc.).

Son otras las calificaciones asignadas a los inmigrantes cuyos documentos de identidad no califican para obtener un visado, renovar un permiso de residencia. Clasificaciones como "sin papeles" no reflejan la condición de extranjeros controlados y registrados tanto en un territorio que no les permitió desarrollar sus anhelos, como en el Estado donde subsisten sin que se les abra un espacio.

Toda designación referida a estos inmigrantes implica connotaciones que deben ser analizadas. La importancia de este análisis reside en que nos 
permitirá comprender un modo de relación con quienes son considerados en base a las cualidades asignadas cuando son denominados de maneras descalificantes. Estas descalificaciones dan nombre a representaciones sociales sobre grupos humanos.

La palabra del poder es usada para nombrar, calificar y descalificar. Ser nombrado puede conducir a hacer parte de la vida y también de la memoria, sea esta una memoria de noble o de infame. Las vidas nombradas en instrumentos del poder pueden construir historias de ficción que dan cuenta de una época transfigurando memorias. Foucault denomina "vidas infames"2 a existencias comunes, sin fama, que quedaron registradas en los archivos luego de un encuentro con un poder que las difama. Estas vidas solo existen en el discurso como recuento de acontecimientos que impulsaron exclusiones. El relato que sobre ellas es posible encontrar en documentos, devela existencias distorsionadas, desacreditadas. La historia que sobre ellas queda registrada, borra sus verdaderas memorias, a causa de un falso reconocimiento sobre las realidades acontecidas a hombres y mujeres sometidos a un discurso del poder que infama.

Las relaciones de comunicación sirven al propósito de excluir por medio de la apropiación de palabras que serán silenciadas o distorsionadas. Igualmente las relaciones de poder pueden servirse de las relaciones de comunicación para dotar de nombres que constituyen hombres infames. Sus voces no requieren ser calladas, ya que han sido descalificadas junto con quienes las portan. Los sujetos nombrados pueden portar nombres que no los representan, nombres que les fueron asignados para desvalorizarlos. Entonces su memoria será desdibujada por una falsa historia. Los hombres infames son denominados como anormales, enfermos, criminales, clandestinos, indocumentados, sin papeles, etc. Estos "nombres" quedan guardados en un registro que los inscribe en una historia infame. Se trata de sujetos calificados negativamente para ser incluidos en un discurso que al desacreditar, somete y margina. Pero el efecto más perverso de ese discurso es que nombra incluyendo en la historia constituida por el registro, para borrar de la memoria. Nombra sujetos que realizan hechos cotidianos, construyendo una ficción sobre ellos, que anula su verdadera identidad. Las vidas infames son vidas hechas anónimas, que intentan resistir a ser sometidas, pero que son objeto del control y la regulación de la población.

Las descalificaciones que designan al inmigrante no nacen arbitrariamente, ellas son un arma que utiliza el poder para someter. El discurso del

\footnotetext{
${ }^{2}$ FOUCAULT, Michel. La vie des hommes infâmes.
} 
poder asigna nombres a los inmigrantes desde diversas instancias destinadas al control social (policía, sistema judicial, psiquiatría, etc.). Esos nombres dicen del espacio social asignado al inmigrante, no de las historias y realidades que ellos transitan. Nombres como "sin papeles", "clandestino", "irregular", etc. producen vidas infames. Pero la desacreditación que estos nombres portan puede llegar a grados aún más perniciosos cuando deshumaniza.

La lógica que subyace todo discurso del poder puede manifestarse en diversos ámbitos. Ella será encontrada paralelamente en el lenguaje médico, jurídico, policial, etc. Es así que las clasificaciones diagnósticas pueden reproducir el sentido de calificativos que aparecen en otros espacios del poder. Un ejemplo de ello es el "Síndrome de Ulises", que expresa la misma lógica con la cual los inmigrantes denominados como "sin papeles" son difamados.

\section{Sobre Ulises y su nombre}

A fin de reconocer el paralelismo que venimos de revelar, comenzamos considerando una cita que Achotegui realiza basándose en la asociación entre la odisea que atraviesa Ulises y la que adjudica a los inmigrantes denominados "sin papeles": “...preguntas cíclope cómo me llamo...voy a decírtelo. Mi nombre es nadie y nadie me llaman todos..."3. A continuación el psiquiatra realiza ese comentario: "Si para sobrevivir se ha de ser nadie, se ha de ser permanentemente invisible, no habrá identidad ni integración social y tampoco puede haber salud mental" ${ }^{4}$. Finalmente, retomando la misma referencia a "La Odisea" ${ }^{5}$, Achotegui ofrece esta explicación sobre la clínica del Síndrome de Ulises:

Habría numerosos aspectos que favorecerían la aparición de sintomatología de tipo confusional. La confusión podría estar ligada a con el tener que esconderse, hacerse invisibles, para no ser retenidos, repatriados (en definitiva el famoso episodio de la Odisea en que Ulises le dice a Polifemo que su nombre es Nadie). Así no es infrecuente encontrar casos de menores que han pasado por numerosos centros tutelados en los que dan un nombre diferente en cada lugar. ¿Cuál es el verdadero? ${ }^{6}$

A fin de develar la lógica paralela existente entre el discurso psiquiátrico y el discurso que descalifica a determinados inmigrantes, a continuación realizaremos algunas comparaciones. Veremos entonces que la representación social sobre los inmigrantes que sostiene la fundamentación teórica

${ }^{3}$ ACHOTEGUI, op. cit., p. 39.

${ }^{4}$ Ibidem.

${ }^{5}$ HOMERO. La odisea.

${ }^{6}$ ACHOTEGUI, op. cit., p. 47. 
de este diagnóstico está guiada por la significación de conceptos tales como: "irregular", "ilegal", "sin papeles", "clandestinos", "indocumentados", etc.

En primera instancia, es necesario observar que la concepción del inmigrante que subyace a estos conceptos se hace visible en el ejemplo arriba citado, al adjudicar como causa de la sintomatología consignada el hecho de "tener que ocultarse". Achotegui aquí toma un ejemplo que él relaciona con el hecho concreto de esconder un nombre, ejemplo en el cual se confunde a los inmigrantes en general con los niños de la calle que emigran a España desde el norte de África. Este encubrimiento de nombres se observa con frecuencia en menores transgresores de diferentes lugares del mundo. Es necesario detenerse ante este error, ya que la asociación general entre transgresión y migración nos remite a los conceptos de anteriormente nombrados. ¿Quién se supone debe ocultarse? ¿Se está hablando de alguien fuera de las normas? ¿Se trata de alguien que se opone al respeto de la ley? ¿Un clandestino?

Decir que alguien está en situación "irregular" implica asociarlo a lo anormal. La irregularidad hace susceptible de ser corregido, de ser encerrado, o de ser excluido; por lo tanto de ser deportado. El adjetivo "ilegal" significa "que es contrario a la ley"7 y al ser utilizado para calificar a algunos inmigrantes ubica a quienes así son denominados del lado de la criminalidad.

Es posible evidenciar aquí, como los términos empleados para denominar a algunos inmigrantes expresan literalmente una condena. Inmigración y delincuencia es una asociación altamente frecuente, asentada en una realidad engañosa. Sin embargo, asociar al inmigrante a la criminalidad implica cerrarle puertas a muchos espacios de potencial integración. Por ello, quedar ubicado en un espacio nominal de criminalidad, hace vulnerable a insertarse. Pero en ese caso, la inserción se circunscribe a un circuito social específico: el carcelario. Foucault ${ }^{8}$ muestra que el delincuente es un producto de institución. En su estudio sobre las prisiones, demuestra que ellas producen delincuencia a fin de poder controlarla. La criminalidad no nace de la marginalidad, sino gracias a inserciones vigiladas. Este filósofo indica que la red carcelaria no excluye, incorpora todo, también lo que reprueba y sanciona. La denominación de ilegal dada a algunos inmigrantes muestra mecanismos que buscan producir un modo de exclusión inclusiva ${ }^{9}$ que circunscribe la inserción del inmigrante a espacios reprobados socialmente.

\footnotetext{
${ }^{7}$ Diccionario de la Real Academia de la lengua Española.

${ }^{8}$ FOUCAULT, Michel. Surveiller et punir. Naissance de la prison.

${ }^{9}$ Cf. AGAMBEN, Giorgio. Homo sacer. Le pouvoir souverain et la vie nue, p. 25-30.
} 
Similar concepción es la de "clandestino", a quien con mayor claridad se refiere la condición de oculto, secreto, escondido de la ley. Esta noción se confunde con una situación de explotación laboral que no es privativa de quienes no pueden regularizarse, pero que es favorecida por la no regularización. El clandestino es segregado de los circuitos laborales protegidos por la ley, lo cual deja a la vista su condición de sin derechos. Se promueve en este caso una situación más compleja que la inclusión en el circuito carcelario. La prisión está regida por el derecho carcelario, el clandestino en cambio se encuentra privado de derechos. ${ }^{10}$

Vemos entonces que el paralelismo de sentidos no se detiene en el circuito de la transgresión a la ley y rebasa en los espacios desprotegidos por el derecho, tomando su forma más extrema al dudar de la identidad de los inmigrantes. Duda que se corresponde al injurioso calificativo "sin papeles", usado para desconocer la validez de los documentos de identidad que portan quienes en esta categoría son destituidos.

La identidad del inmigrante queda cuestionada en el acto de no otorgar valor a los documentos portados por los "indocumentados", "sin-papeles", "clandestinos", etc. De este modo se los descalifica violentamente dejándoles fuera de todo reconocimiento. En una intervención improvisada realizada en apoyo a inmigrantes, en 1996, Derrida ${ }^{11}$ reflexionaba respecto a lo que se dice al nombrar a los "sin papeles", entonces considera que este nombre pone en cuestionamiento la identidad. Preguntándose sobre lo que les falta a los "sin" papeles, responde que les falta el derecho al derecho, les falta la dignidad humana que se les deniega.

Todas las denominaciones que nombran esta "categoría" de inmigrantes desconocen, descalifican, niegan derechos, discriminan, cuestionan la identidad. Todas ellas - antepuestas por prefijos "i", "in", o la preposición "sin" - niegan valor a quienes denominan, les sustraen reconocimiento en tanto humanos. De este modo se llega a consentir privarlos de sus derechos, convirtiéndolos en "homo sacer"12.

La asignación de pérdida de identidad en los inmigrantes es algo recurrente en el discurso del poder que habla sobre ellos. No siempre se especifica si se hace referencia a la identidad cultural de origen (la cual más que perderse se transforma de variadas maneras según cada historia de migración), si se trata de la identidad cívica que se les rehúsa, o si se trata de

${ }^{10}$ Ibidem, p. 27-28.

11 DERRIDA, Jaques. Manquements du droit à la justice (mais que manque-t-il donc aux "sanspapiers").

12 AGAMBEN, op. cit., p. 81 y siguientes. 
la identidad psíquica. Achotegui delimita bien su referencia a la identidad, ya que relaciona el síndrome descrito por él con síntomas característicos de trastorno por despersonalización, trastornos de identidad disociativos, etc. ${ }^{13}$ El psiquiatra que se permite denominar "Nadie", y dudar de la identidad de los inmigrantes sobre los cuales habla, no se cuestiona las consecuencias de la duda que plantea. Más bien, afirma una respuesta al adjudicar a esos inmigrantes una pretendida "pérdida de identidad". Identificando a los inmigrantes que él diagnostica con quien él cree que se denomina a sí mismo "nadie", no hace más que reiterar, replicar y reforzar las representaciones expresadas en los apelativos antes analizados, que descalifican a algunos inmigrantes. El diagnóstico de Síndrome de Ulises repite un discurso sobre determinados inmigrantes, que les niega identidad, les sustrae derechos y pretende hasta llegar a anular sus existencias.

\section{Sobre la identidad de Ulises y el síndrome que lleva su nombre}

La categorización de migrantes no es privativa de nuestros tiempos, aún en tiempos míticos, podemos hallar una variada gama de categorías de viajeros (Argonautas, guerreros, desterrados, etc.). Los relatos de la mitología griega nos hablan de hombres que emprenden importantes andanzas, así como de quienes deben realizar desplazamientos que un destino desventurado les depara.

Un destacado ejemplo de un viaje mítico se despliega en una gran odisea, donde un hombre heroico, con su astucia, vence los avatares de un largo viaje de regreso a su hogar. La mitología griega cuenta que Odiseo (llamado Ulises por los romanos) era un hombre heroico, rey de Ítaca y destacado guerrero en Troya. Las andanzas de este héroe durante un retorno que duró diez años fueron relatadas por Homero en sus celebres poemas épicos.

Este ejemplo, en una interpretación bastante particular, ha sido tomado como base para calificar a los inmigrantes de la actualidad en la descripción del "Síndrome de Ulises". Sin embargo, una reflexión detenida sobre el mito de Ulises puede darnos la clave para comprender la verdadera problemática que afecta a los inmigrantes que con los calificativos antes considerados son (des)identificados.

\section{Sobre Ulises y su astucia}

La cita tomada por Achotegui para ser referida a los inmigrantes debe ser considerada teniendo en cuenta su contexto. Ulises engaña a Polifemo, a

\footnotetext{
${ }^{13}$ ACHOTEGUI, Joseba, La depresión en los inmigrantes. Una perspectiva transcultural.
} 
fin de poder evitar ser devorado por este último. Ulises hace creer al Cíclope que su nombre es Outis, lo cual significa nadie. Sin embargo, se trata de un juego de palabras, ya que las silabas ou-tis se pueden reemplazar por mè-tis. Pero mètis significa astucia. La astucia hace parte de las características más sobresalientes de este hombre. ${ }^{14}$ La respuesta de Ulises es una de sus astucias, es un ardid que le permitirá escapar de la furia de los cíclopes. Esta respuesta ejemplifica una forma de resistencia. Tal vez, Ulises nos podría ayudar a entender de otra manera a los escasos inmigrantes que se ven obligados a esconder su identidad a fin de cegar el ojo del control migratorio y así evitar ser deportados. No se trata de una ausencia de identidad, más bien se trata de una estrategia de resistencia a fin de evitar ser clasificado de manera descalificante, ser tratado como sin derechos, ser tratado como nadie. No enseñar una identidad desacreditada, no mostrar una identidad que no será reconocida, es un intento de conservarla sin permitir que sea cuestionada en base a prejuicios raciales.

Sin embargo, apenas Ulises logra escapar, no duda de gritar su nombre, y contrariando las advertencias precavidas de sus compañeros, se empeña en exaltar su identidad:

...Ya alejados, me dispuse a burlarme de nuevo de Polifemo, aunque mis compañeros se oponían, pero insistí y grité: -Si alguien te pregunta ciclope, quien te reventó el ojo, dile que fue Ulises, hijo de Laertes y rey de Itaca. ${ }^{15}$

Ulises no se conforma con destacar su verdadero nombre, inscribe el mismo en su linaje, da cuenta de su estatuto, y se comporta de acuerdo al nombre que lleva como enojado. Ello tendrá como consecuencia que Poseidón pueda identificarlo y condenarlo a terribles pruebas antes de que logre arribar a su tierra. A pesar de ellas, Ulises no admite ser tratado como nadie.

Si bien hay inmigrantes que como estrategia de resistencia esconden su identidad ante situaciones específicas, gran parte de ellos, tal como lo hace Ulises, no duda en resaltarla, aún si las consecuencias de ello pueden ser terribles pruebas que retarden el arribo a la meta en el viaje que ellos se proponen. Un ejemplo cotidiano de ello es la reiterada necesidad que lleva a muchos extranjeros a corregir sus nombres cuando son mal pronunciados, lo cual en ocasiones los hace víctima de burlas, desprecios, discriminaciones. Aún así, siguen resaltando el nombre que portan, a fin de hacerlo reconocer.

${ }^{14}$ VERNANT, Jean-Pierre. CEuvres Religions Rationalités Politique 80.

${ }^{15}$ OMERO, op. cit., p. 77-78. 


\section{Sobre Ulises y su marca}

Pero, es necesario destacar que el secreto escondido en el mito de Ulises, que puede ayudar a comprender la situación de muchos extranjeros, no trata de un ocultamiento de la identidad, sino de su reconocimiento.

Este secreto no se encuentra en la palabra Outis (nadie), sino en el verdadero nombre del héroe. Para develarlo es necesario aclarar que Odiseo significa enojado. Pero la palabra Ulises está formada por los términos oulos (herida) e isches (muslo).

Se cuenta que Odiseo era hijo de Anticlea, quien a su vez era hija del famoso ladrón Autólico. Al nacer fue visitado por su abuelo quien lo tomó en sus rodillas y le dio el nombre de Odiseo. Eligió llamarlo enojado teniendo en cuenta que el niño sería víctima de sus enemistades. Pero para compensarlo prometió que si alguna vez lo visitaba le daría parte de sus posesiones para calmar su ira.

Durante los rituales de pasaje a la adolescencia, Odiseo fue herido por un jabalí en el muslo. La cicatriz producida por esa herida le quedó hasta su muerte. Esto sucede mientras el héroe visita a su abuelo, quien le entregó los dones ofrecidos. ${ }^{16}$

Muchos años más tarde, la marca dejada en esa importante etapa de la vida va a permitir que el protagonista de esta historia, estando disfrazado de mendigo, pueda ser reconocido por su nodriza. Es en el reconocimiento del entorno que centraremos la problemática del viajero y entre ellos del inmigrante. El viajero deja temporalmente su espacio geográfico. El inmigrante deja su espacio geográfico y su espacio social, para ingresar a lugares donde es un desconocido. En tanto no recupere nuevos espacios geográficos y sociales no puede tener existencia social. La existencia social solo se logra a partir del reconocimiento por parte del otro, el reconocimiento de características propias de cada ser humano, el reconocimiento de una historia individual, el reconocimiento de roles asumidos, la ubicación en un estatuto social. El relato del regreso de Ulises a su tierra da un ejemplo de ello.

El largo tiempo que Ulises permaneció perdido durante el viaje de retorno que había emprendido al terminar la guerra de Troya, hizo que lo dieran por muerto. A causa de ello la isla de Ítaca estaba colmada de príncipes que cortejaban a Penélope, la reina aparentemente viuda. Estos príncipes pretendían ocupar el lecho, y con ello el trono de Ulises. Pero la fiel Penélope, esperando a su marido, engañaba a sus pretendientes prometiendo elegir a uno de ellos en cuanto terminara un tejido que realizaba durante el día y que destejía por las noches. Cuando Ulises logra arribar a Ítaca y conoce la

\footnotetext{
${ }^{16}$ Cf. GRAVES, Robert. Los mitos griegos.
} 
situación que vivía su familia va a espiar a los pretendientes de su mujer, para lo cual se disfraza de mendigo. Penélope hace llamar al supuesto mendigo con la expectativa de que este le trajera noticias de su esposo. Cuando va a verla, ella no lo reconoció. Ulises le relata mentiras, haciéndole creer que su esposo llegará pronto a casa. Penélope después de escucharlo ordena a Euriclea, la nodriza del rey, que bañe los pies de quien piensa es un mendigo. Euriclea reconoce inmediatamente a Ulises al ver la cicatriz que este conserva en su muslo. Para la nodriza la identidad del rey, gracias a la marca que le da su nombre, queda develada tras su disfraz. ${ }^{17}$

El reconocimiento de la identidad del rey es la clave que le permite retornar a su trono, a su familia, a su tierra; es decir al estatuto social que siempre había ocupado. No solo él, sino todos aquellos que lo rodean recuperan su lugar social a partir de ese reconocimiento. Cuando Ulises es reconocido por su hijo Telémaco, cada uno de ellos afirma su lugar en la familia. Un vínculo constitutivo de sus identidades se puede restituir cuando al reconocerse mutuamente devienen padre e hijo. Igualmente el padre de Ulises, o sus sirvientes necesitan restaurar la relación social de la cual depende su estatuto. Ulises vuelve a ser hijo, vuelve a ser amo, a partir de que lo reconocen como tal. Y siendo reconocido por su esposa puede volver a ocupar el lecho de rey. A medida que Ulises va siendo reconocido por todos ellos, recupera su estatuto social. ${ }^{18}$ Ulises nunca pierde su identidad, tal como muchos inmigrantes, solo pierde el reconocimiento necesario para tener existencia social en el lugar donde sea que se encuentren.

\section{Todos me llaman nadie}

Ulises deja su tierra, se convierte en un héroe de la guerra, intenta regresar pero se pierde, recorre tierras lejanas, el tiempo pasa, llega hasta los confines de la tierra, del tiempo y le ofrecen la inmortalidad, pero prefiere regresar a su vida. Ulises no acepta ser llamado nadie. Jean-Pierre Vernant ${ }^{19}$ considera que justamente la característica del héroe es conservar su identidad. Pero esa identidad debe ser reconocida por su entorno, para existir socialmente. Es significativo que mientras Ulises estaba perdido fuera dado por muerto por quienes deseaban ocupar su estatuto social (esposo de Penélope, rey de Ítaca). El no reconocimiento por parte del otro deja sin estatuto, Ilevando a una muerte social. A quien todos llaman Nadie, a quien su identidad le es cuestionada se le produce una muerte social.

\footnotetext{
17 Ibidem

${ }^{18}$ VERNANT, op. cit.

${ }^{19}$ Ibidem.
} 
El psicoanálisis, la psicología social, la sociología, la antropología coinciden en mostrar cómo la identidad psíquica y social se constituye a partir del reconocimiento del otro. Este reconocimiento implica la dotación de un nombre que porta los deseos de los padres y el entorno más cercano, que a su vez inscribe en un linaje familiar y en una red social, que por lo tanto otorga un estatuto social. Atribuir a alguien un estatuto implica otorgarle un reconocimiento (incluso cuando se trata de un estatuto desvalorizado). El reconocimiento es necesario para resguardar la sobrevivencia en un marco de inserción social, que asigna un estatuto humano a cada individuo que deviene sujeto. La ausencia de reconocimiento hace objeto de una deshumanización que deja exento de todo resguardo por parte de la comunidad.

Todo inmigrante posee una identidad, que lo posiciona en un estatuto social. Cuando un inmigrante al ser tratado como nadie deja de ser reconocido no pierde su identidad, pierde su estatuto social, quedando sometido a una deshumanización.

El mito de Ulises nos permite descubrir que la verdadera problemática del inmigrante está en la manera en que es representado por el discurso de la sociedad receptora. La existencia social siempre depende del reconocimiento del otro. Por ello, no reconocer el lugar que ocupa un inmigrante en la sociedad en la cual habita, borrar su estatuto social, cuestionar su identidad, es una manera de deshumanizarlo llegando a negar su existencia. Y una existencia negada no cuenta con pertenencia ni protección alguna.

\section{Entre identidad perdida y pérdida de los derechos humanos}

En "La decadencia del Estado-Nación y el final de los derechos del hombre" 20 , Hannah Arendt relata que la Primera Guerra Mundial dejó serias consecuencias en Europa: inflación, paro, guerras civiles, migraciones. Estas migraciones marcaron una diferencia respecto a otras anteriores, ya que quienes las protagonizaron no fueron bien recibidos en ningún lugar. Tanto las desnacionalizaciones, como las repatriaciones acrecentaron quienes se encontraban sin hogar. Progresivamente fueron perdiendo todo, quedaron sin estado, se convirtieron en apátridas, hasta que llegaron a perder los "inalienables" derechos del hombre. La proclamación de inalienables referida a los derechos del hombre entendía que ellos eran aplicables a todo hombre con independencia de toda pertenencia a alguna nación. Sin embargo, no existía ninguna institución capaz de garantizar estos derechos ante los apátridas. Los derechos civiles en los distintos países suponían estar basados en los derechos del

${ }^{20}$ ARENDT, Hannah. Los Orígenes del totalitarismo. 
hombre; pero resultaban inaplicables para quienes no poseían una ciudadanía determinada. Dado que los apátridas no eran protegidos ni representados por ningún gobierno, terminaron teniendo que vivir sea en la ilegalidad (al punto de llegar en ocasiones a preferir cometer una infracción a la ley, para así ser protegidos por el derecho penal y dejar de ser sin derechos), o bajo la ley de excepción de los tratados para las minorías. Los tratados de las minorías expresaban que solo los nacionales podían ser ciudadanos, y únicamente a estos últimos correspondía una completa protección legal. Entonces, los derechos del hombre, no pudiendo disociarse de los derechos del ciudadano, dejaron a muchos seres humanos carentes de toda protección de sus derechos. Por ello Arendt afirma respecto a las víctimas de esta situación "que la abstracta desnudez de no ser nada más que humanos era su mayor peligro" ${ }^{21}$. El fundamento de los derechos humanos que entendía proteger al ser humano en tanto tal, fracasó frente a quienes no podían ampararse en otra cualidad que la de ser específicamente un humano. Aquellos que pierden todas las cualidades políticas distintivas, y únicamente guardan su pertenencia a la humanidad, lo hacen solo en tanto especímenes de la especie animal que comprende a los hombres. Es así como se llegó a tomar al campo de internamiento como una solución posible frente al problema de los desplazados. La privación de todo estatuto legal crea las condiciones que permiten la deshumanización ocurrida en los campos de concentración.

Arendt muestra que hay condiciones externas al sujeto que lo abandonan fuera del derecho. Ellas solo se hacen posibles anulando los límites de la ley. Esta anulación es factible de afectar a todo humano, pero afecta siempre a quien carece de una comunidad que lo proteja.

A partir de la lectura de este texto de Arendt, Agamben ${ }^{22}$ subraya la paradoja que aquí se pone de manifiesto por medio de la figura del refugiado, quien debería ser la encarnación de los derechos del hombre, pero por el contrario es quien los pone en cuestionamiento. Esta figura permite mostrar que no es posible seguir entendiendo la proclamación de derechos del hombre como dotada de valores eternos metajurídicos. Para Agamben, estos derechos representan la figura originaria que realiza una inscripción de la vida natural en el orden jurídico-político del Estado-Nación.

Como su significado lo muestra, el Estado-Nación hace del nacimiento el fundamento de su soberanía. En realidad, ya desde su mismo título, la declaración de 1789 refleja una ambigüedad que la marca: "Declaración de

${ }^{21}$ Ibidem, p. 424.

22 AGAMBEN, Giorgio. Moyens sans fins. Notes sur la politique. 
los derechos del hombre y del ciudadano". No queda claro si se refiere a dos realidades autónomas, o si se trata de un conjunto. Luego, la lectura de los tres primeros artículos muestra la unión del principio de la soberanía a la nación/nacimiento.

La figura del refugiado plantea una crisis a la ficción originaria de la soberanía, dado que quiebra la identidad entre hombre y ciudadano. El refugiado, privado de su nacionalidad y por ende de sus derechos, es la nueva figura del "homo sacer", que puede ser muerto impunemente y no puede ser sacrificado. Los campos de la muerte son testimonio de ello. Es preciso recordar que los primeros campos de Europa fueron creados a fin de establecer un espacio de control para los refugiados. Su apertura preparó una terrible sucesión, que comenzó con estos campos de internamiento y continuó con los campos de concentración y de exterminio. A estos últimos solo llegaban quienes habían perdido previamente su nacionalidad. Con el paso de los años, los campos de refugiados diseminados por diferentes lugares siguen exhibiendo la vida nuda que en ellos encierran.

Agamben considera que la denominada inmigración "ilegal" se ubica en el mismo espacio límite, donde el hombre pierde sus derechos en tanto tal, por distinguirse del ciudadano. Estos inmigrantes por no ampararse en la protección de su propio Estado, al igual que los refugiados que temían ser repatriados, aún poseyendo una nacionalidad de origen, se transforman en "apátridas de hecho". Su condición de hombres no les garantiza protección alguna en las puertas de los campos destinados a la detención de inmigrantes.

El termino i-legal podría aparecer como bien aplicado si en vez de referirse a una transgresión de la ley diera cuenta de un fuera de la protección de la ley. El concepto de inmigrante ilegal que es Ilamado nadie muestra cómo una confusión entre identidad civil e identidad personal, impide el reconocimiento de los derechos que deberían ser inalienables para todo humano.

\section{Consecuencias de ser llamado nadie}

La deshumanización dirigida a los inmigrantes opera desde la sociedad receptora. Las consecuencias de los discursos deshumanizantes pueden adquirir distintos grados, que van desde el consentimiento de injusticias, pasando por no respeto de derechos y pudiendo llegar hasta el aniquilamiento.

Marie-Claire Caloz-Tschopp ${ }^{23}$ considera que:

\footnotetext{
${ }^{23}$ CALOZ-TSCHOPP, Marie-Claire. Les étrangers aux frontières de l'Europe et le spectre des camps.
} 
Pour pouvoir comprendre le sens potentiel, ultime de la chaîne des dispositifs et des outils de rétention, de détention et d'expulsion d'étrangers aux frontières d'Europe, ce qu'il faut accepter de percevoir, de voir, de penser, dans la profondeur historique en observant les faits actuels, c'est la réalité d'une invention politique qui a créé les humains superflus, l'anéantissement. ${ }^{24}$

Retomando estos últimos conceptos de la obra de Hannah Arendt'25, Caloz-Tschopp destaca las tres etapas descritas por Arendt, que permitieron al poder nazi instituir un régimen de humanidad superflua, entre los cuales se cuenta: matar la persona jurídica, matar la persona moral y borrar las diferencias entre los individuos, matar la identidad. Ella precisa que la expresión nazi Vernichtung (aniquilamiento) enuncia una negación radical de existencia.

Para Arendt el desarraigo puede ser la condición preliminar a la superfluidad. Ella entiende el desarraigo como la condición de ausencia de lugar en el mundo, que sea reconocido y garantizado por los otros. En tanto que la superfluidad es definida como la ausencia de pertenencia en el mundo.

Si bien el hombre superfluo es un producto al que aspira el estado totalitario, no deja de existir en otras condiciones políticas. Al respecto Hannah Arendt enuncia:

El peligro de las fábricas de cadáveres y de los pozos del olvido es que hoy, con el aumento de la población y de los desarraigados, constantemente se tornan superfluas masas de personas si seguimos pensando en nuestro mundo en términos utilitarios. Los acontecimientos políticos, sociales y económicos en todas partes se hallan en tácita conspiración con los instrumentos totalitarios concebidos para hacer a los hombres superfluos. La tentación implícita es bien comprendida por el sentido común utilitario de las masas, que en la mayoría de los países se sienten demasiado desesperadas para retener una parte considerable de su miedo a la muerte. Los nazis y los bolcheviques pueden estar seguros de que sus fábricas de aniquilamiento, que muestran la solución más rápida para el problema de la superpoblación, para el problema de las masas humanas económicamente superfluas y socialmente desarraigadas, constituyen tanto una atracción como una advertencia. Las soluciones totalitarias pueden muy bien sobrevivir a la caída de los regímenes totalitarios bajo la forma de fuertes tentaciones, que surgirán allí donde parezca

\footnotetext{
24 "Para poder comprender el sentido potencial, ultimo de la cadena de dispositivos y de útiles de retención, de detención y de expulsión de extranjeros en las fronteras de Europa, lo que es preciso aceptar de percibir; de ver; de pensar, en la profundidad histórica observando los hechos actuales, es la realidad de una invención política que ha creado los humanos superfluos, la aniquilación" (Traducción realizadas por la autora del artículo).

${ }^{25}$ ARENDT, op. cit.
} 
imposible aliviar la miseria política, social o económico en una forma digna del hombre. ${ }^{26}$

Las categorías asignadas a los inmigrantes a quienes se les niega la posibilidad de residir donde ellos se lo proponen se dirigen a franquear las etapas que pretenden la institución de una humanidad superflua. Estas categorías permiten transitar un camino que comienza con la deportación y llega a implementación de campos de refugiados, o campos de retención de extranjeros en zonas fronterizas. Cuestionar la identidad de un inmigrante, borrarla llamándolo nadie, son grandes pasos en ese camino.

\section{Nadie: N.N.}

N.N es una triste sigla que hace referencia a las palabras "Nacht und Nebel", que expresan la manera en que el régimen nazi ocultaba todo resto de la vida y de la muerte que no deseaba reconocer. Para el sistema policial estas letras significan "No name", y se utilizan para hablar de los sospechosos sin dar sus nombres, o para referirse a los indocumentados. En Argentina, durante la última dictadura militar, se enterraron como N.N (ningún nombre) numerosos desaparecidos en fosas comunes. Con el objetivo de recuperar sus nombres, sus cuerpos deben ser objeto de complejos estudios realizados por equipos de antropólogos forenses, médicos y biólogos. En este caso, estos estudios permiten que los N.N. dejen de serlo, recuperando las historias del fin de sus vidas, y permitiendo a sus familiares realizar las ceremonias fúnebres pertinentes, que dejen procesar un duelo por ellos. El objetivo del trabajo de estos profesionales es lograr devolver la identidad a los cuerpos que estudian, lo cual solo se puede lograr al final de su trabajo, cuando los cuerpos son entregados a sus familiares para que puedan realizar los rituales que permitan restablecer su memoria.

Muchos cuerpos hallados como N.N. siguen sin ser identificados. Las vidas por las que esos cuerpos transcurrieron no quedaron inscriptas en la historia. Las vidas despojadas de memoria construyeron una historia habitada por hombres infames. En cambio, las vidas despojadas de memoria, pero además también de historia, fueron transformadas en no vividas.

La sigla N.N. se refiere a sin nombre, a vida y muerte no reconocida; es decir a quien es tratado como "Nadie". Esto nos advierte sobre el riesgo que implica la deshumanización a la cual un inmigrante es sometido cuando su identidad es cuestionada. Ser privado de reconocimiento conduce a una

${ }^{26}$ Ibidem, p. 616. 
Mi nombre es nadie y nadie me llaman todos... sobre la identidad del inmigrante

desprotección tal que permite hacer desaparecer las huellas que marcan el camino y hacen la historia de múltiples inmigrantes.

\section{Conclusión}

Retomando la pregunta por la verdadera problemática que afecta a los inmigrantes denominados sin papeles, vemos que podemos tomar a Ulises como modelo explicativo. Mediante una interpretación del mito de Ulises podemos representar la situación específica de algunos inmigrantes, los inmigrantes llamados "sin papeles", tal como lo propone Achotegui. Es decir, este mito, en este abordaje, puede ejemplificar solo la condición de inmigrantes cuyo estatuto social, en alguna tierra a la cual llegaron, no fue reconocido.

Sin embargo, frente al discurso psiquiátrico que patologiza, es necesario hacer resaltar que las andanzas de Ulises nunca hablan de pérdida de identidad. Más bien, durante el prolongado destino que nuestro héroe atraviesa lejos de su casa, siempre afirma su identidad. El modelo explicativo de la problemática que aquí debemos hacer visible es el ocurrido a Ulises al finalizar su viaje. Esta problemática trata de una sociedad que, en vez de ver un rey en nuestro héroe, ve un mendigo. Entonces reiteramos: la problemática que ocurre a estos inmigrantes es la ausencia de reconocimiento desde su estatuto social, que se produce anulando su identidad.

Nadie significa: "pron. indef. 1. Ninguna persona. 2. Persona insignificante" ${ }^{27}$ Quien así es llamado no es reconocido como persona significativa, o ni siquiera como persona; por lo tanto es desvalorizado al punto de quedar deshumanizado. Quien es considerado "humano" será sujetado a un poder que lo protege y somete de ese modo quedará resguardado por el derecho. Por el contrario, quien queda atrapado en los límites de las representaciones sobre lo humano es excluido por una representación ficticia que lo anula. Entonces no puede ser protegido, por lo tanto queda en situación de desamparo social. Ser llamado Nadie, tiene consecuencias que no deben ser olvidadas.

\section{Bibliografía}

ABELES, Marc. Anthropologie de la globalisation. Paris: Payot, 2008.

ACHOTEGUI. Joseba. Emigrar en situación extrema: el Síndrome del inmigrante con estrés crónico y múltiple (Síndrome de Ulises). Norte de Salud mental, n. 21. 2004, p. $39-52$.

. La depresión en los inmigrantes. Una perspectiva transcultural. Barcelona:

${ }^{27}$ Diccionario..., op. cit. 
Editorial Mayo, 2002.

AGAMBEN, Giorgio. Homo sacer. Le pouvoir souverain et la vie nue. Paris: Seuil, 1997.

Moyens sans fins. Notes sur la politique. Paris: Payot, 1995

AGIER, Michel. Aux bords du monde, les réfugiés. Paris: Flammarion, 2002.

ARENDT, Hannah. Los Orígenes del totalitarismo. Madrid: Taurus ediciones, 1974.

BALIBAR, Étienne, Sans-papiers: I'archaïsme fatal. Paris: La découverte, 1999.

- Violencias, identidades y civilidad. Para una cultura política Global.

Barcelona: Ed. Gedisa, 2005.

BAUMAN, Zygmunt. Le coût humain de la mondialisation. Paris: Hachette, 1999.

BUTLER, Judith. Ce qui fait une vie. Essai sur la violence, la guerre et le deuil. Paris: La Découverte, 2010.

. La vie psychique du pouvoir. Paris: Editions Léo Scheer, 2002.

. SPIVAK, Gayatri. L'Etat global. Paris: Editions Payot \& Rivages, 2007.

. Le pouvoir des mots. Discours de haine et politique du performatif. Paris:

Editions Amsterdam, 2004.

. Humain, inhumain. Paris: Editions Amsterdam, 2005.

. Vie précaire Les pouvoirs du deuil et de la violence après le 11 septembre 2001. Paris: Editions Amsterdam, 2005.

CALOZ-TSCHOPP, Marie-Claire. Les étrangers aux frontières de l'Europe et le spectre des camps. Paris: La dispute, 2004.

DERRIDA, Jaques. Manquements du droit à la justice (mais que manque-t-il donc aux «sans-papiers»?). In DERRIDA, Jaques. Marx en jeu. Paris: Decartes \& Cie, 1997.

Diccionario de la Real Academia de la lengua Española, vigésimo segunda edición.

FOUCAULT, Michel. Dits et écrits I y II. Paris: Gallimard, 2001.

. Histoire de la folie à l'age classique. Paris: Gallimard, 1972.

. Il faut défendre la société. Cours au collège de France 1976. Paris:

Gallimard, 1997.

. La volonté de savoir. Histoire de la sexualité. Paris: Gallimard, 1976.

. Le pouvoir psichiatrique. Cours au collège de France 1973-1974. Paris:

Gallimard, 2003.

1999.

. Les Anormaux. Cours au collège de France 1974-1975. Paris: Gallimard,

. Surveiller et punir Naissance de la prison. Paris: Gallimard, 1975.

GRAVES, Robert. Los mitos griegos. Madrid: Alianza Editorial, 1985.

HOMERO. La odisea. Santiago de Chile: Editorial Zigzag, 1973.

VERNANT, Jean-Pierre. CEuvres Religions Rationalités Politique. Paris: Editions du Seuil, 2007. 


\section{Abstract \\ My name is nobody and nobody is what everyone calls me...on the identity of the immigrant}

By considering a parallelism between the different domains ofthe dominant discourse on immigrant classification, this paper strives to reveal the logic that underlies it. The consequences of this discourse and the problems it causes to those classified by it are also discussed. This paper proposes a reflection on the consequences and risks implied by the lack of social recognition of some categories to which the immigrants are subjected to.

Keywords: Immigrants; Identity; Recognition; Dehumanization.

Recibido para publicación en 22/02/2013.

Aceptado para publicación en 29/04/2013.

Received for publication on February, 22 2013.

Accepted for publication on April, 29 $9^{\text {th }}, 2013$. 